\title{
Nachrichten
}

Jubiläumstagung der Tschechoslowakischen Ornithologischen Gesellschaft. - Die Tschechoslowakische Ornithologische Gesellschaft feierte ihr 30jähriges Bestehen, indem sie Ende Oktober 1956 in Prag eine große Tagung veranstaltete und hierzu auch einige ausländische Ornithologen einlud. Unter dem Vorsitz des Präsidenten der C. O. G., Dozent Dr. Watter C (Narodni Museum) am Wenzelsplatz am 27. und 28. Oktober eine lange Folge fachlicher Vorträge gehalten, die die verschiedensten Gebiete der Vogelkunde betrafen, darunter auch das der funktionellen Anatomie (L. Sigmond: Rallen; Z. Veserovskx: Tauchenten) und der Histologie (M. Kurma: Bursa Fabricii). Den etwa 160 aus der Tschechoslowakei Erschienenen hatten sich als Gäste der Gesellschaft Prof. G. P. Dementiew (Moskau), zwei polnische Ornithologen sowie der Berichterstatter beigesellt. Am ersten Abend wurde den Teilnehmern in einem Filmtheater Erlesenes vorgeführt, darunter lehrreiche und technisch meisterliche Filme des rühmlich bekannten Naturphotographen Dr. V. J. StaneK, ferner Heinz Stelmanns Spechtfilm "Zimmerleute des Waldes". Zur Besichtigung der beiden, am Schilfufer großer Seen idyllisch gelegenen und gut ausgestatteten Beobachtungswarten der C. O. G. wurde vom 29. bis 31. Oktober eine Exkursion, die bis Budweis führte, in Autobussen durch die abwechslungsreiche Landschaft Südböhmens unternommen. Sie war verbunden mit einer Führung durch zwei Schlösser mit imposanten Sammlungen (ehemaliger Besitz des Erzherzogs Franz Ferdinand bzw. der Fürsten SchwarZENBERG). In der Vogelsammlung des Schwarzenberg'schen Jagdschlosses steht als besondere Merkwürdigkeit ein Birkhahn (Lyrurus tetrix) von weiblicher Färbung, also ein Gegenstück zu dem hennenfedrigen Auerhahn der Sammlung KoHTs in Moskau (J. f. Orn. 1956 p. 231). Die in einem Flügel des palastartigen NarodniMuseums zu Prag aufgestellte zoologische Schausammlung, durch die uns ausländịsche Gäste deren Direktor, Herr Dr. O. ŠtepankK, und Herx Dr. Hanzak führten, enthält als ornithologische Kostbarkeiten einen Nestor productus, ein schönes Paar der Labrador-Ente (Camptolaimus labradorius) ${ }^{\mathbf{1}}$ ) und zwei Riesenalken (Pinguinus: impennis), von denen einer das Winterkleid trägt (vgl. W. Buastus, J. f. Orn. 1884 p. 106). Durch den am steilen Hang des Moldautales und auf dem Plateau weithin sich dehnenden Zoologischen Garten, vorbildlich in seiner großzügigen und geschmackvollen Anlage und überraschend reich an selten gezeigten Säugetieren und Vögeln, führte uns an einem der folgenden Tage der Direktor, Herr Dr. Purkynje. Stark beeindruckt von der freundschaftlichen Fïrsorge, die mir allenthalben zuteil geworden war, und von der erfolgreichen Aktivität der vielen tschechoslowakischen Ornithologen trat ich am 2. November die Rückreise nach Berlin an. Es steht zu hoffen, daß die angesehene "Sylvia“ in die Lage versetzt wird, bald wieder regelmäßig zu erscheinen und in ihrem nächsten Heft einen ausführlichen Tagungsbericht $\mathrm{zu}$ veröffentlichen.

E. Stresemann

1) Diese beiden Labrador-Enten sind noch in keinem Verzeichnis aufgeführt worden. Ich vermisse sie bei Dutcher (1891), bei Rothschild (1907) und J. C. Phillips (Natural History of the Ducks IV (1926) p. 62-63).

\section{Berichtigung zu Band 97}

Seite 451. Im Schema zum Vortrag Koxnig ist das Wort „Kröte“ durch „Krähe" zu ersetzen. 